\title{
OS MANUAIS DOS INQUISIDORES: UMA LEITURA COMPARATIVA ENTRE A INQUISIÇÃO E O SALAZARISMO
}

\author{
José Luciano de Melo ${ }^{1}$
}

RESUMO: O artigo compara os títulos O Manual dos Inquisidores (1376), de Nicolau Eymerich e O Manual dos Inquisidores (1998), de António Lobo Antunes, mostrando algumas similaridades entre a ação do Santo Ofício da Inquisição e a ditadura salazarista figurada no romance).

PALAVRAS-CHAVE: Nicolau Eymerich; António Lobo Antunes; inquisição; salazarismo; ditadura.

ABSTRACT: The essay intends to compare the titles $O$ Manual dos Inquisidores (1376), Nicolau Eymerich's work, and O Manual dos Inquisidores (1998), António Lobo Antunes' work, showing some similarities between the action of the Inquisition and the fall of Salazar's dictatorship in the novel.

KEYWORDS: Nicolau Eymerich; António Lobo Antunes; inquisition; salazarism; dictatorship.

\footnotetext{
${ }^{1}$ Doutorando em Literatura Portuguesa pela Universidade de São Paulo
} 
Por que Lobo Antunes, num livro contextualizado na ditadura salazarista e na Revolução dos Cravos, utiliza como título Manual dos Inquisidores? O que pretende o autor português, ao nomear a obra que, a priori, nada tem de "manual", e muito menos de "Inquisição"? A começar pelo título da obra, que não é um título inédito, fruto da imaginação de Lobo Antunes. Manual dos Inquisidores surgiu em 1376, escrito pelo eclesiástico Nicolau Eymerich, e depois readaptado e aumentado em 1585 pelo espanhol Francisco de La Peña. Este Manual se constitui em uma obra severa, restringindo-se à atuação e funcionamento do Santo Ofício em relação aos julgamentos:

(...) des blasphèmes, des sacrilèges, des astreientes aux foundementes mêmes de l'Église, la violation des jugements et des sacrées, des injustices, des calomnies et des cruatés dont les catholiques sont les victimes. Par l'effect de l'hérésie, la vérité catholique s'affaiblit; (...) L'historie ancienne en témoigne. Et le présent le démontre, qui offre à nos regards le spectacle de régions prospères (...) à cause de l'hérésie, des plus grandes calamités. (EYMERICH, 1973, p.48)

O livro não apenas trata da legitimidade e da operacionalidade dos inquéritos medievais, mas também observa aspectos inerentes da sociedade da época. A Inquisição portuguesa, que perdurou com grande longevidade entre os séculos XVI e meados do XIX, garantiu sua mão de ferro graças a um rígido cumprimento eclesiástico no julgamento das atitudes e ações contrárias a suas determinações, intimidando toda a população em nome do bem comum e, por meio da repressão, assegurando o domínio sócio-político da Igreja em toda a sociedade.

Além de uma série de relatos de heresias e as penas para cada atentado contra as determinações da Igreja, o documento medieval prescreve regras para uma sociedade moldada nos padrões que o Santo Ofício determinara em sua época. Neste sentido, a sociedade é a "personagem" protagonista na obra de Eymerich, caracterizando-se num corpus em potencial a ser encarcerado pelos pareceres eclesiásticos. Deste modo, o medieval Manual dos Inquisidores prefigura-se num pungente relato de uma sociedade aprisionada num regime punitivo, que ditava leis e normas a serem realizadas por todos os membros do meio social, com terríveis julgamentos e penas se estes não as cumprissem, em "prol do bem comum".

Ora, neste viés, o contemporâneo Manual dos Inquisidores aproxima-se no foco temático do homônimo medieval: a opressão e as conseqüências de regimes 
governamentais (o período inquisitório e a ditadura salazarista) no corpus social, que Lobo Antunes delimitará em uma família portuguesa. Assim, servindo-se de uma ironia perspicaz, o autor de As naus confere as conseqüências da queda do governo ditatorial à decadência moral do protagonista Francisco, o patriarca da família e ministro de Estado de Salazar, outrora administrador influente do poder e repressão.

Lobo Antunes arquiteta de tal maneira a trama, que todos os personagens têm relação, de parentesco ou não, com Francisco, o que de certo modo, a partir deste elo, as envolve num círculo muito íntimo com o próprio governo salazarista. Esta estratégia de divisão e influência de poderes nas personagens de Lobo Antunes remete-as como a um sistema doutrinário de governo, em que há divisões preestabelecidas com objetivos em comum. E mais uma vez o contemporâneo autor nos surpreende com sua peculiar sutileza, o que, a priori, denota total liberdade artística, seja pelo estilo despojado de escrita ou anulação de um narrador onisciente, exacerbando a polifonia dos personagens, encobre um rígido esquema de composição, assemelhando-se a um tipo de poder: a Inquisição. Leiam-se as palavras de José Mattoso sobre a divisão de poderes no Santo Ofício:

\begin{abstract}
Essa acção pode ser analisada a três níveis: a) o controle do clero (heresias, solicitação, comportamento moral) - talvez a função mais importante mas menos visível, que coloca os inquisidores num estatuto mais prestigiado do que o dos seus confrades; b) a formação de "quadros" que serão aproveitados para a administração da Igreja ou para administração da Coroa (bispos, desembargadores, juízes, conselheiros); c) o controle e a disciplina da população (...). (MATTOSO, 1993, p.161)
\end{abstract}

Observe-se, então, a relação hierárquica do poder inquisitorial e o esquema de enredo que Lobo Antunes organiza no Manual dos Inquisidores: a) o controle do clero - a ditadura de Salazar; b) a formação de "quadros" - Ministério de Estado (Francisco); c) o controle e disciplina da população — demais personagens interligados e submissos a Francisco-Salazar.

Temos aí um macabro paralelo entre a execução do controle e da repressão, o governo de Salazar e a Inquisição, que tornou:

(...)sistemático e constitucional o uso que se fazia dos meios pérfidos, atacando de frente a humanidade, a família, o caráter, a virtude: 
triturando o homem em tudo o que há de nobre em nome de uma razão de Estado transcendente.(...) (MARTINS, 1972, p.328)

Todavia, se a Inquisição trouxe à nação portuguesa medo e terror, por outro lado o funcionamento, enquanto instituição, foi muito eficaz durante o tempo em que esteve no poder, controlando as atividades intelectuais e repreendendo opiniões. Não foi à toa que perdurou ao longo de dois séculos, pois seus regulamentos e determinações foram aplicados no mais intenso rigor. "(...) Num país onde os serviços públicos se caracterizam sempre pela má organização e ineficiência, o Santo Ofício constitui uma surpreendente excepção (...)” (SARAIVA, 1993, p.187). Neste sentido, Hermano Saraiva ironiza o fato de que a partir da instalação da Inquisição em Portugal tem-se um modelo de administração pública ímpar na história dos regimes governamentais lusitanos.

Nas aparições públicas, para a prática dos "serviços de Deus", os agentes inquisidores demonstravam toda a intolerância e autoridade que infligiam ao público, como no seguinte relato:

\begin{abstract}
Depois da estirada procissão, no couce, vinham os alabardeiros da Inquisição e, a cavalo, os oficiais do conselho supremo, inquisidores, qualificadores, relatores, e mais sequazes da corte. Os sinos dobravam pausadamente nas torres das igrejas. (...) Cordões de tropa impediam que o povo invadisse, na praça, o recinto do Auto. (...) Na da esquerda estava o rei, D. João III, piedosamente satisfeito na sua fé, como espírito duro, mas sincero e forte; (...) $\mathrm{Na}$ outra, da direita, levantavam-se o trono e o dossel do cardeal D. Henrique, depois rei, e agora infante inquisitor-mor, ladeado pelos membros do tribunal sagrado, nos seus bancos. (MARTINS, 1972, p.332)
\end{abstract}

Agora, observemos a seguinte passagem na obra de Lobo Antunes, quando uma comitiva do governo salazarista invade a loja de Dona Dores:

(...) e nisto uma tropa do Governo na loja, um furriel que é mais que capitão a fazer-me continência com medalhas e cordões na farda, polícias à paisana a guardarem a rua, um jipe aqui e outro ali com metralhadoras e tudo a vedarem o trânsito, (...) e o senhor ministro a caminhar pelo meu estabelecimento como um príncipe, um cavalheiro da idade do meu marido mas muito mais bem conservado, muito mais bonito, muito mais distinto que se notava ser logo de outra educação, outro estar, outra presença, um cavalheiro da idade do meu marido mas sem palavrões nem nariz de bêbado (...) (ANTUNES, 1998, p.274) 
Estes dois relatos servem-nos de instrumento para mostrar como a Inquisição e o salazarismo, nas características de represália e intimidação ao público, têm pontos em comum. Nota-se que, se na instituição medieval eram utilizados cordões de tropa para impedir a entrada do povo, no regime salazarista jipes com metralhadoras bloqueiam o trânsito, evitando transtornos à comitiva e ao ministro de Estado, Francisco; e se o rei D. João III aparece com espírito duro, mas satisfeito na fé que exige o cargo que ocupa, o ministro Francisco caminha na loja como um príncipe, um ser que, para a realidade daquele local, sobrepuja-se apenas por não pronunciar palavrões nem possuir "nariz de bêbado". Lobo Antunes toca na ferida e desmascara toda a mediocridade moral da sociedade portuguesa contemporânea ao relatar que, mesmo com toda a repressão e autoritarismo de uma ditadura que cerceou a liberdade civil e intelectual da nação, o submisso povo lusitano aceitou ou, como vimos, idolatrou o regime salazarista, personificado em Francisco. Sobre esta passividade de aceitação de uma autoritária administração, podemos traçar outro paralelo com a Inquisição, quando Saraiva argumenta que: "A actividade inquisitorial pôde exercer-se sem fortes reacções internas, porque não existia uma classe média com independência económica e mental, e também esta situação lhe é anterior”. (SARAIVA, 1993, p.132)

Lobo Antunes insere elementos reais que se fundem no enredo, como se cada um perdesse sua identidade (ficcional e histórica) para dar vazão a uma única "realidade", como podemos ver neste excerto:

(...) o professor Salazar, que mandava no país inteiro, nos militares, na igreja, a fazer-me perguntas, a preocupar-se comigo, a achar-me graça, a oferecer-me torradas, refrescos, bolos de ovos, taças de morangos, o professor Salazar, de perninhas magras juntas, com um guardanapo nos joelhos, a pedir-me que lhe falasse da Praça do Chile, da minha mãe, da loja, o professor Salazar a tratar-me por senhora (...) o professor Salazar que eu não acreditava que prendesse pessoas, as mandasse torturar, as embarcasse nos paquetes de África para morrerem de mordeduras de cobras venenosas. (ANTUNES, 1998, p.304-305)

Nesta passagem, em que Isabel narra o encontro com Salazar, observa-se que, embora o ditador não discurse diretamente na conversa, Lobo Antunes o faz participar de um modo quase direto: o ministro pergunta, oferece, pede, trata por senhora a esposa de Francisco, caracterizando no plano da ficção a figura real de um indivíduo. Ou seja, ao afirmar-se que Salazar "contracena" com Isabel 
(...) há uma transformação da própria identidade. Cria-se uma nova identidade, composta da união de pólos contraditórios. Esta altera a identidade anterior de cada um dos componentes, assim como na montagem - cinematográfica ou literária - também se alteram os elementos postos em conexão(KOTHE, 1986, p.11).

Cria-se a representação de uma realidade no plano ficcional, no qual personagens reais e irreais se cruzam num sentido figurado, que, em nosso caso, dá-se na intenção de Lobo Antunes retratar um período sócio-político português, caracterizando-se num procedimento alegórico, que seria:

representação concreta de uma idéia abstrata. Exposição de um
pensamento sob forma figurada em que se representa algo para indicar
outra coisa. Subjacente ao seu nível manifesto, comporta um outro
conteúdo. É uma metáfora continuada, como tropo de um pensamento
em causa por outro, ligado ao primeiro por uma relação de
semelhança. (KOTHE, 1986, p.90)

Neste viés, o autor de O Manual dos Inquisidores utiliza-se de um contexto real — ditadura de Salazar e Revolução dos Cravos —, vivida num plano ficcional — família do patriarca Francisco, a fim de representar a sociedade moderna portuguesa em meio às constantes mudanças governamentais de Portugal.

Então é possível dizer que uma narrativa alegórica pode transformar experiências individuais em experiências coletivas. No caso de $O$ Manual dos Inquisidores, por exemplo, podemos dizer que as experiências individuais vivenciadas pelas personagens apresentadas são a expressão das experiências vividas por toda a nação portuguesa naquele momento histórico. As personagens do romance chegam a ser caricaturais, representando determinada classe social que ocupam, e, mais do que isso, representando determinados comportamentos ou posturas frente aos fatos experimentados, o que muito as aproxima da impiedosa inibição e autoridade exercida pela Inquisição. As muitas repetições colocadas pelo autor dentro dos relatos e comentários das personagens têm a função de reafirmar idéias e concretizar uma imagem de cada personagem. Francisco é a representação do contraponto do poder: "Faço tudo o que elas querem mas nunca tiro o chapéu da cabeça para que se saiba quem é patrão", tendo aqui o chapéu como uma insígnia do poder que pode ser associada à idéia de coroa; depois temos o retrato de sua própria decadência: "Xixi 
senhor doutor xixi"; seu filho Francisco assume uma imagem de "bobo": "O menino é parvo, ou faz-se?"; e assim em todas as narrações, criando imagens das personagens, de suas lembranças e de seus anseios.

Neste sentido, autor e leitor iniciam uma interessante relação através da alegoria presente na obra. Quanto mais encoberta estiver a verdade no texto, maior será o desafio e a excitação de desvendá-lo; e Lobo Antunes parece disposto a provocar cada vez mais seu leitor, ao declarar que

(...) Passou a me interessar mais como personagem principal o Portugal, mesmo que apareça em filigrana ou silhueta a personagem principal das histórias que tenho tentado escrever. Mas existia desde o primeiro livro a preocupação em tentar descobrir uma nova maneira de dizer. E o que a gente vai procurando, essa maneira diferente de dizer, é sobretudo um desafio da pessoa do narrador (...) (GOMES, 1993, p.138-139).

Percebe-se que o autor de As naus se engaja no desafio de cada vez descobrir novas maneiras de dizer, ou seja, aguçar os espíritos vorazes dos leitores de sua obra, como fazia o poeta grego Alano. Além disso, o autor português dá a pista do mote de seu objetivo literário: a personificação de Portugal, como se este fosse o agente e o representado em seus romances, justificando todo o empreendimento de retratar a sociedade lusitana da metade do século XX, em O Manual dos Inquisidores.

No entanto, para a elaboração deste enredo, que privilegia a investigação cuidadosa de fatores, Lobo Antunes arquiteta, minuciosamente, todos os acontecimentos, a fim de excitar a interpretação de todos os sentidos, em princípio, ocultos. Assim, o tratamento das frases denota o caráter áspero, rígido e sombrio que permeia o romance. Neste sentido, Mongelli ressalta que:

(...) é necessário cuidado especialíssimo na construção do narrador, cuja aparência de isenção exige malabarismos retóricos eficazes. Está aí o fulcro de imagens que se sucedem em avalanche, de impressões do real manifestadas por personagens das mais diversas origens e condições sociais, num caleidoscópio de vozes que metaforiza a complexidade do real. Lobo Antunes vem depurando tal polifonia como alicerce de suas narrativas. (MONGELLI, 1998, p.6)

Esta exaltação do sentido oculto da composição artística, privilegiada por Lobo Antunes, parece ser a amostragem de uma repressão ditatorial que pulverizou, quase que 
por completo, a liberdade de uma geração de artistas lusitanos. Essas obsessões de romper com as regras, sejam gramaticais ou de um hipócrita pudor contra palavrões, insere Lobo Antunes na galeria de uma tendência da literatura portuguesa atual. Segundo Álvaro Cardoso Gomes,

(...) o que representaria, afinal, essa ânsia de falar, essa busca discursiva, essa aventura no meio das palavras? Entre outras coisas, a resistência ao mundo de opressão, que, acima de tudo, se traduziu por um esforço sistemático em instaurar uma linguagem convencional, (...). O que surpreende, pois, no romance português contemporâneo, é a sua atuação na linguagem. Nos casos mais extremados, mais revolucionários, as vozes existem para afirmar sua independência em relação a um discurso oficial (...). Mas que discurso acabará essa voz por instaurar? O discurso da procura, o discurso périplo, que erra para resgatar a linguagem, para fazê-la recuperar sua magia. (GOMES, 1993, p.124)

Da mesma forma, as personagens do romance parecem ser levadas por uma força superior. Os fatos simplesmente lhes acontecem e cada uma reage como sabe ou pode, sendo assim instrumentos de suas próprias manifestações inconscientes, e representando o sentimento de toda a nação através da ideologia salazarista.

O Manual dos Inquisidores cria mistérios com suas formas não convencionais e criatividade, mas, na medida em que se atenta para sua tese, elaborada através do processo alegórico, é como se houvesse um desvendamento que dá àquele mistério uma razão de ser.

A polifonia de que faz uso, não definindo um ponto de vista único no romance, constrói um Portugal de mentes perdidas, ocupadas cada uma com suas questões individuais, enquanto são levadas, quase sem perceberem, a um incógnito futuro. Assim, nem o patrão e nem a cozinheira têm governo de sua própria vida e, mesmo num patamar social privilegiado, todos estão sujeitos à maior queda. A Revolução só foi executada quando o Estado Novo já estava decadente, e os partidos de esquerda, que tanto influenciaram o povo a lutar pela Revolução, nem sequer, por fim, ficaram no governo. Aqui não interessa a ascensão e queda de uma personagem ou outra, mas sim a decadência coletiva.

Do mesmo modo, o homônimo medieval revela-se num sorumbático retrato social. Sob a tutela do regime inquisitorial não existem individualidades, mas apenas a operacionalidade de um sistema opressor. Os mecanismos punitivos não somente 
condenam o indivíduo e suas práticas subversivas como, num patamar maior de alcance, moldam toda a atividade individual em parâmetros preestabelecidos de convivência.

Se no texto de Eymerich o exercício da punição está configurado para o didatismo da execução, no de Lobo Antunes parte-se da premissa de que todos estão sumariamente executados. Seja como for, em ambos os casos, é o homem encarcerado nas grades de suas próprias ideologias. A questão é saber de que lado cada um está.

\section{Referências bibliográficas}

ANTUNES, Antonio Lobo. O Manual dos Inquisidores. Rio de Janeiro: Rocco, 1998.

CURTIUS, Ernest Robert. Literatura Européia e Idade Média Latina. Brasília: INL, 1979.

EYMERICH, Nicolau \& PEÑA, Francisco. Le Manuel des Inquisiteurs. France: Mouton, 1973.

GOMES, Álvaro Cardoso. A voz itinerante. São Paulo: Edusp, 1993.

KOTHE, Flávio. A alegoria. São Paulo: Ática, 1986.

MARTINS, Oliveira. História de Portugal. Lisboa: Guimarães Editores, 1972.

MATTOSO, José. História de Portugal. Lisboa: Editorial Estampa, vol. III, 1993.

MONGELLI, Lênia Márcia. O cais moderno da angústia portuguesa. São Paulo: in Jornal da Tarde, Caderno de Sábado, 11/07/98.

SARAIVA, José Hermano. História de Portugal. Lisboa: Alfa, 1993 